\title{
Infecções pelos vírus das hepatites B e C e 0 carcinoma hepatocelular na Amazônia oriental
}

\author{
Hepatitis B and C virus infection and the hepatocellular carcinoma \\ in the East Amazon, Brazil
}

\author{
Esther Castello Branco Mello Miranda ${ }^{1,2}$, Lizomar de Jesus Pereira Moia ${ }^{1}$, Ivanete do Socorro \\ Abraçado Amaral ${ }^{1}$, Maria Silvia de Brito Barbosa ${ }^{1}$, Simone Regina Souza da Silva Conde ${ }^{1}$, \\ Marialva Tereza Ferreira de Araújo ${ }^{2}$, Ermelinda do Rosário Moutinho da $\mathrm{Cruz}^{2}$, Samia Demachki ${ }^{2}$, \\ Gilberta Bensabath ${ }^{3}$ e Manoel do Carmo Pereira Soares ${ }^{3}$
}

\begin{abstract}
RESUM0
Com o objetivo de contribuir para um melhor conhecimento do envolvimento das infecções pelos vírus das hepatites B e C, na etioepidemiologia do CHC na Amazônia Oriental, estudou-se 36 pacientes em Belém-PA. Foram avaliados marcadores sorológicos e a pesquisa do HBV-DNA e HCV-RNA pela reação em cadeia da polimerase. Observou-se etilismo em 33,3\% e cirrose em 83,3\%. Marcadores sorológicos das infecções pelo HBV e HCV foram encontrados respectivamente em 88,9\% e 8,3\%. 0 HBsAg foi encontrado em 58,3\%; anti-HBc em 86\%; anti-HBe em 85,7; HBeAg em 9,5\%; anti-HBc IgM em $57,1 \%$. O HBV-DNA foi detectado em 37,7\% e em 65\% dos HBsAg positivos; o HCV-RNA em 8,5\% e em 100\% dos antiHCV positivos. AFP esteve alterada em 88,9\% e acima de $400 \mathrm{ng} / \mathrm{ml} \mathrm{em} 75 \%$ dos casos. Conclui-se que a infecção pelo HBV parece ter importância na etiologia do $\mathrm{CHC}$ e ressalta-se a importância de implementar programas de vacinação e detecção precoce do tumor.
\end{abstract}

Palavras-chaves: Hepatite B e C. Hepatoma. Sorologia. Biologia molecular.

\begin{abstract}
In order to contribute to a better understanding of the possible role of hepatits $B$ and $C$ in the etiopathogenis of HCC in the East Amazon, there were studied 36 patients in Belém/PA. Serological hepatitis markers were evaluated and polymerase chain reaction assays were used to detect HBV-DNA and HCV-RNA. Alcohol abuse was observed in 33.3\% and cirrhosis in 83.3\%. In $88.9 \%$ of the sample, one or more hepatitis B markers were positive. Also, 8.3\% those patients had anti-HCV simultaneously positive. The HBsAg serological test was positive in $58.3 \%$; anti- $\mathrm{HBc}$ in $86 \%$; anti- $\mathrm{HBe}$ in $85.7 \%$; anti$\mathrm{HBe}$ in $9.5 \%$; IgManti- $\mathrm{HBc}$ in $57.1 \%$. The HBV DNA was found in $37.7 \%$ and in $65 \%$ of the HBsAg positive. The HCV RNA was detected in $8.5 \%$ and in $100 \%$ of ' the patients positive to anti-HCV. The AFP was above the normal value in $88.9 \%$ of patients, with levels up to $400 \mathrm{ng} / \mathrm{ml}$ in $75 \%$ of them. In conclusion, hepatitis B virus infection seems to be important in the etiology of HCC and improving measures such immunization and screening in the risk population should be emphasyzed.
\end{abstract}

Key-words: Hepatitis B and C. Hepatocellular carcinoma. Serology. Molecular biology.

As infecções crônicas pelo vírus da hepatite B (HBV) e pelo vírus da hepatite $\mathrm{C}(\mathrm{HCV})$ estão associadas à maioria dos casos de $\mathrm{CHC}^{2}{ }^{23}$. No Brasil, cerca de 68,5\% dos casos estão relacionados à etiologia viral ${ }^{9}$. Por meio de técnicas de hibridização molecular, demostrou-se que a integração do HBV-DNA, no cromossoma do hospedeiro, ocorre durante 0 curso de infecção persistente pelo HBV e precede 0 aparecimento do $\mathrm{CHC}^{21}$. 0 desenvolvimento de $\mathrm{CHC}$ em ratos transgênicos reforça 0 papel trans-ativador do gene $\mathrm{HBxAg}$ na carcinogênese ${ }^{15}$. 0 HCV-RNA não se integra ao genoma do hospedeiro, mas por levar a doença necro-inflamatória, agiria como promotor da carcinogênese por aumentar as chances

\footnotetext{
1. Programa de Hepatopatias Crônicas da Fundação Hospital Santa Casa de Misericórdia do Pará, Belém, PA. 2. Universidade Federal do Pará. 3. Instituto Evandro Chagas da Fundação Nacional de Saúde, Belém, PA.

Endereço para Correspondência: Profa Esther Castello Branco M. Miranda. Rua Oliveira Belo 535, Umarizal, 66090-000 Belém, PA, Brasil.

Tel: 91 242-9022

e-mail: miranda@amazon.com.br.
} 
de rearranjamentos nas seqüências do $\mathrm{DNA}^{3}$. Entretanto, alguns estudos mostram a persistência e replicação do genoma do HCV no $\mathrm{CHC}$ mesmo ausência de cirrose ${ }^{6}$. 0 CHCé muito freqüente em determinados locais, como a China, sudeste Asiático e África. A incidência varia com a área geográfica, raça, sexo e idade ${ }^{10}$. No Brasil, foram registrados, no ano de 1992, 3.827 óbitos em virtude de neoplasia maligna de fígado e vias biliares, segundo dados do Ministério da Saúde 7 . Contudo, em conseqüência da falta de registros que expressem a verdadeira situação, não existem ainda informações seguras quanto à incidência do CHC. Observam-se variações decorrentes de grandes diferenças regionais e alguns dados sugerem uma incidência elevada na Amazôniå ${ }^{8}$. Devido a escassez de dados relacionados à incidência dos marcadores sorológicos das hepatites virais em pacientes com CHC em nosso meio, ressalta-se a necessidade de estudos que contribuam para um melhor conhecimento do envolvimento das infecções pelos vírus das hepatites $\mathrm{B}$ e $\mathrm{C}$ na etioepidemiologia do $\mathrm{CHC}$.

\section{CASUÍSTICA E MÉTODOS}

As observações foram feitas em Belém-PA, Brasil em pacientes atendidos em três hospitais públicos no período de jan/1992 a jan/1999. Para efeito de definição de caso de CHC utilizaram-se os seguintes critérios: sinais e sintomas clínicos com diagnóstico compatível pela US abdominal e/ou TC de abdome e níveis de AFP acima de 400ng/ml; e/ou diagnóstico histopatológico. Investigou-se 36 pacientes, sendo $24 \mathrm{com}$ diagnóstico histopatológico de CHC e doze que atenderam aos outros critérios já especificados. Avaliou-se a clínica, etilismo ( consumo igual ou superior a 80g/dia de etanol), sorologia para os marcadores das hepatites virais, dosagem sérica de AFP, exames de biologia molecular ( pesquisa dos ácidos nucléicos virais HBV-DNA e HCV-RNA). Biópsia hepática foi realizada conforme indicações e restrições. Os exames sorológicos para as hepatites B, C, eD ( para os casos HBsAg positivos) e a dosagem de AFP foram realizados com métodos imunoenzimáticos (ELISA). Todos os soros foram examinados para o HBsAg, antiHBc, anti-HBs e anti-HCV. Os testes para $0 \mathrm{HBsAg}$ e anti-HBC foram realizados com kits do laboratório Organon Teknika ${ }^{\circledR} \mathrm{e}$ os positivos para $0 \mathrm{HBsAg}$ foram testados para $0 \mathrm{HBeAg}$, anti$\mathrm{HBe}$, anti-HBc IgMe anti-HD. A detecção do anti-HBs e dosagem de AFP foram realizadas com kits do Laboratório Abbott ${ }^{\circledR}$, considerando-se como valor de referência $10 \mathrm{ng} / \mathrm{ml}$. As dosagens de AFP foram avaliadas até a diluição de $74.000 \mathrm{ng} / \mathrm{ml}$. Para detecção do anti-HCV, utilizaram-se kits do laboratório Ortho ${ }^{\circledR}$ (ORTHO ${ }^{\mathrm{TM}}$ HCV 3.0 ELISA Test System). Em todos os testes sorológicos, os resultados foram considerados duvidosos quando a densidade óptica ficou 20\% acima ou abaixo do valor de corte, para 0 EIA e MEIA. A pesquisa do anti-HCV foi suplementada por Ensaio Immunoblot, Recombinant Immunoblot Assay ( RIBA II e/ou LIATEK III). Considerou-se como caso anti-HCV positivo, aqueles soros que tiveram o diagnóstico suplementado por Immunoblot positivo. Realizou-se coletas específicas de soro para a pesquisa (qualitativa e quantitativa) do HBV-DNA e o HCV-RNA com kits do Laboratório ROCHE
( AMPLICOR HBV MONTOR ${ }^{\mathrm{TM}}$, AMPLICOR ${ }^{\circledR}$ HCV e AMPLICORHCV MONITOR ${ }^{\mathrm{TM}}$ ), que utilizam a reação em cadeia pela polimerase (PCR) para amplificação e hibridização do DNA e RNA. Utilizou-se para análise estatística os programas EPI INFO (versão 6.0) e Bioestat for Window (versão 1.0$)^{1}$. Os testes utilizados foram: Qui-quadrado, Kruskal-Wallis, Komorogov-Smirnov e Mann-Witheney. Estabeleceu-se em $0,05(5 \%) 0$ nível de rejeição $(\mathrm{p} \leq 0,05)$.

\section{RESULTADOS}

Nos 36 pacientes estudados, houve predomínio do sexo masculino ( $\mathrm{p}<0,01)$ com 86,1\% (31/36) pacientes masculinos e 13,9\% (5/36) femininos (relação M/F 6,2 /1). Média e mediana encontradas foram respectivamente de 50,8 e 53,0 anos (amplitude 6-81). Afaixa etária predominante foi entre 50 e 60 anos $(\mathrm{p}<0,05)$.

0 Estado do Pará foi responsável por 88,9\% da casuística, sendo os restantes do Maranhão (5,6\%) e do Amapá ( 5,6\%). Belém (27,8\%) foi 0 município de procedência mais freqüente, seguido por Altamira (PA) (8,3\%), Macapá (AP) e Turiaçu (MA) com 5,6\% (Figura 1).

Lavrador ( $38,9 \%)$ foi a ocupação mais freqüente. Cinquenta e três por cento dos pacientes eram procedentes da zona rural e 47\% da zona urbana. Em relação aos sintomas e sinais, dor abdominal e hepatomegalia foram os mais freqüentes encontrados em 94,4\% dos pacientes. Etilismo foi encontrado em 33,3\% e cirrose em 83,3\% dos casos. Mediante a aplicação da classificação de Child-Pugh, estes pacientes apresentaram-se em $53,3 \%$ como classe $C$ e $26,7 \%$ como classe B.

A análise dos marcadores sorológicos das hepatites virais demostrou que 88,9\% (32/36) dos casos apresentavam um ou mais marcadores do HBV e do HCV, sendo o HBsAg positivo em 58,3\% (21/36) dos casos. Foram anti-HCV positivos, 8,3\% (3/ 36) dos casos. Algum marcador do HBV esteve presente em todos os casos anti-HCV positivos. 0 anti-HD não foi encontrado. 0 anti$\mathrm{HBc}$ foi o marcador mais freqüente, sendo positivo em 86\% (31/ 36) ; associado ao HBsAg em 58,3\% (21/36) e associado ao antiHBs em 25\% (9/36). 0 anti-HBc isolado foi positivo em 2,8\% (1/ 36) dos casos. Em 11,1\% (4/36) dos casos não observou-se a ocorrência de marcador sorológico de infecção pelo HBV ou pelo HCV ( Figura 2).

Os pacientes HBsAg positivos (21/36), também foram testados para 0 anti-HBc IgM, HBeAg, anti-HBe. 0 HBeAg foi encontrado 9,5\%, 0 anti-HBe em 85,8\% dos casos. Em 4,7\% (1/21) ambos estavam negativos. 0 anti-HBc IgM foi positivo em $57,1 \%$ dos casos. A positividade do anti- $\mathrm{HBc}$ IgM no total de casos estudados foi de 33,3\% (12/36). Não ocorreu positividade para 0 anti-HBc IgM entre os casos com ausência de marcador de infecção do HBV. Entre os casos anti-HBc IgM positivos, (12/21), dois foram também HBeAg positivos (2/21). Comparando-se os casos HBsAg-positivos e os HBsAgnegativos e a idade em anos, observou-se que a mediana de idade dos casos positivos e dos casos negativos são respectivamente 46 e 65 anos ( $p<0,0035)$. Já para os casos 


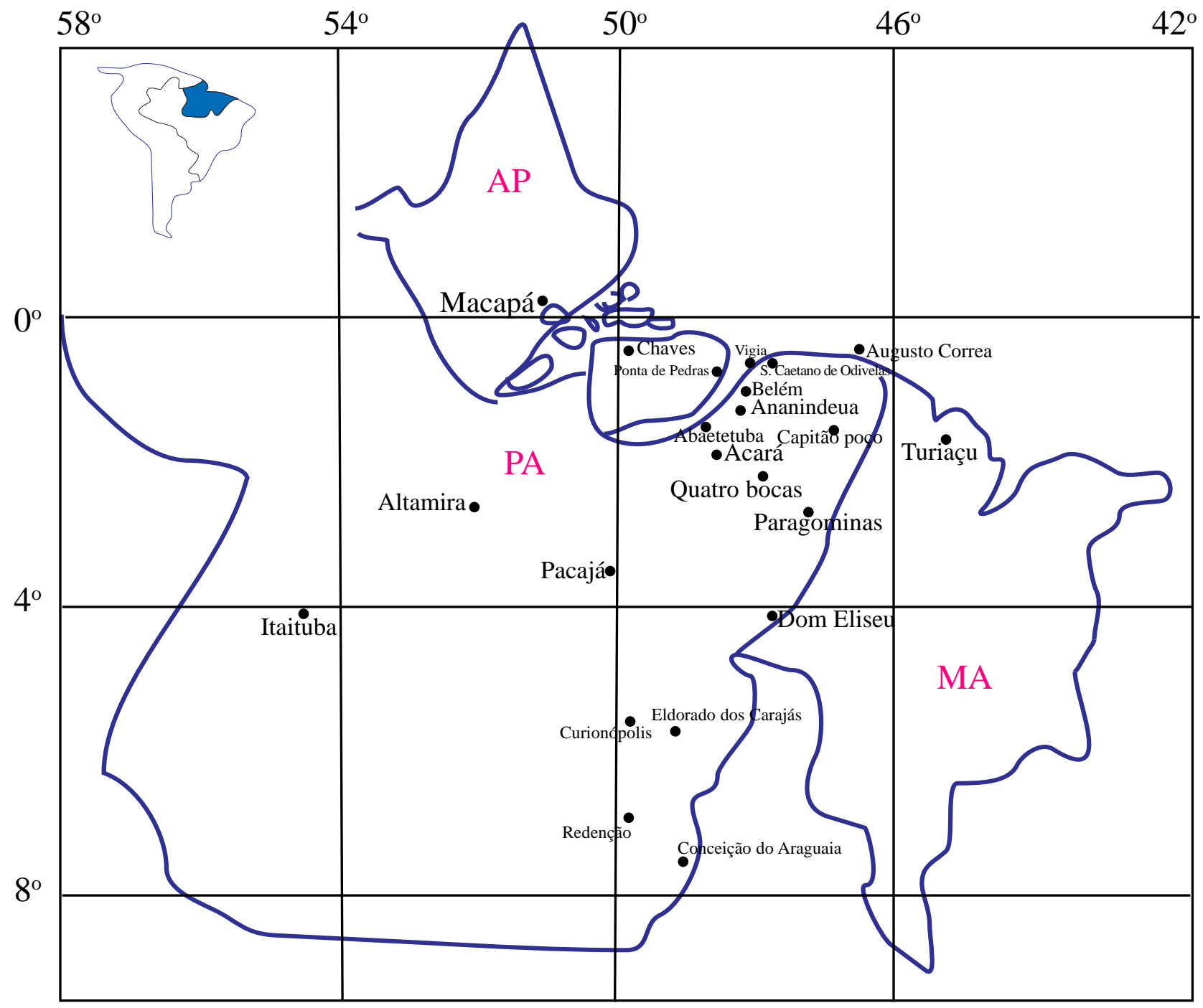

Figura 1 - Distribuição da procedência por município em 36 casos de CHC na Amazônia oriental (1992-1999).

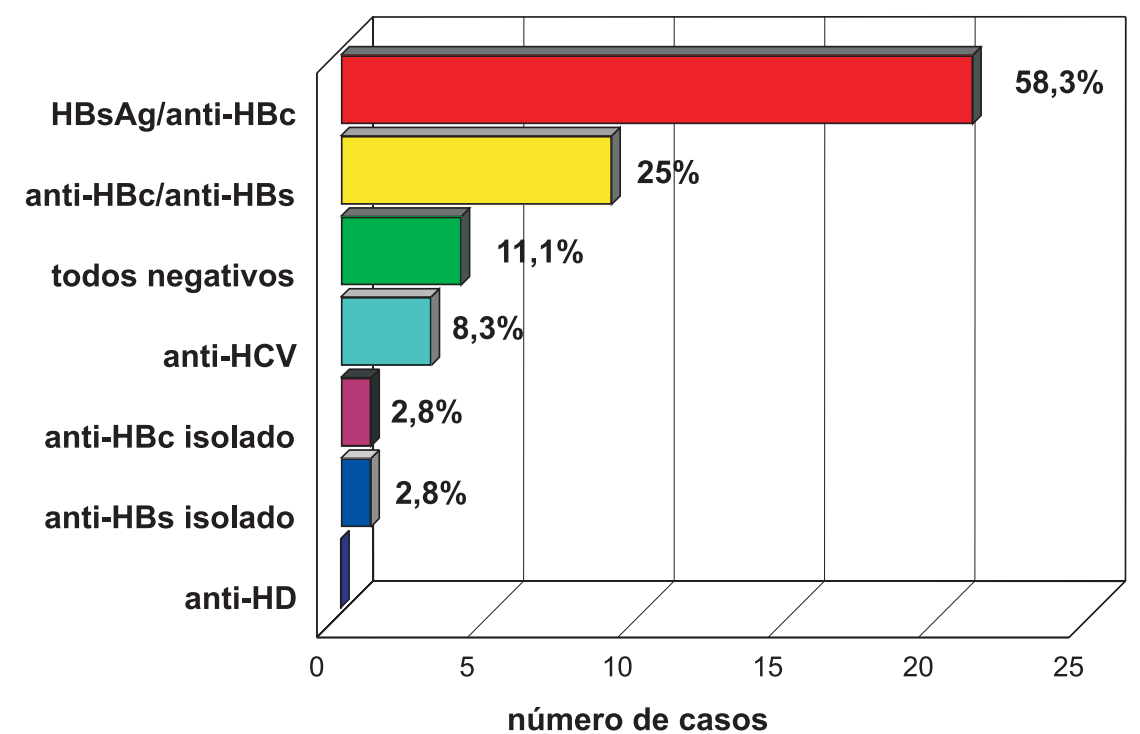

Figura 2 - Perfil dos marcadores sorológicos das hepatites B, C e D, em 36 casos de carcinoma hepatocelular na Amazônia oriental (1992-1999). 
anti-HCV positivos e os anti-HCV negativos, a comparação entre as medianas de idade respectivamente de 68 e de 51 anos não foi significativa.

0 HBV-DNA e o HCV-RNA foram pesquisados em 97,2\% dos pacientes. 0 HBV-DNA foi positivo em 37,7\% (13/35) e entre os 21 casos HBsAg positivos, foi positivo em 65\% (13/20) como mostra a Tabela 1.

Tabela 1 - HBV-DNAe a presença do HBsAg, HBeAg, anti- $\mathrm{HBe}$, anti-HBc IgM em 35 casos de CHC na Amazônia oriental (1992-1999).

\begin{tabular}{lll}
\hline & \multicolumn{2}{c}{ HBV-DNA } \\
\cline { 2 - 3 } & positivos & negativos \\
\hline HBsAg positivo & 13 & 7 \\
HBeAg e anti-HBc IgM Positivos & $2(15,4 \%)$ & 0 \\
Anti-HBe e anti-HBc IgM Positivos & $5(38,5 \%)$ & $3(42,9 \%)$ \\
Anti-HBe positivo e Anti-HBc IgM negativo & $6(46,1 \%)$ & $4(57,1 \%)$ \\
HBsAg negativo & 0 & 15 \\
Anti-HBs e anti-HBc Positivos & 0 & $9(60,0 \%)$ \\
Anti-HBc positivo & 0 & $1(6,7 \%)$ \\
Anti-HBs positivo & 0 & $1(6,7 \%)$ \\
Todos negativos & 0 & $4(26,6 \%)$ \\
Total & 13 & 22 \\
\hline
\end{tabular}

Houve concordância com sete casos anti-HBc IgM positivos e com dois casos HBeAg positivos 0 HBV-DNA quantitativo realizado em 20 casos HBsAg positivos variou de 1.283 a 1.160 .00 cópias/ $\mathrm{ml}$ (média geométrica=53,51E+031). 0 HCV-RNA foi positivo em 8,5\% (3/35) dos casos e em concordância com os três casos anti-HCV positivos pelo teste de imunnoblot. 0 HCV-RNA quantitativo variou de 1.643 a 214.185 cópias por ml.

A dosagem de AFP, realizada em todos os pacientes, mostrou amplitude de 2,0 a 74.792ng/ml. Em 11,1\% a titulação foi inferior a 10ng/ml. Em 75\% mostrou-se acima de 400ng/ml e em 27,8\% a titulação foi igual ou superior a $70.000 \mathrm{ng} / \mathrm{ml}$. Os casos HBsAgpositivos, apresentaram mediana de AFP de $9.800 \mathrm{ng} / \mathrm{ml}$ e os HBsAg-negativos de 412ng/ml ( $p=0,0074)$. Os níveis de AFP foram maiores naqueles indivíduos que evoluíram para 0 óbito e nos portadores de doença hepática crônica $(p<0,05)$. Os casos HBsAg positivos eram maisjovens ( $p=0,0035)$ e com níveis mais elevados de $\operatorname{AFP}(p=0,0014)$, em relação aos casos HBsAg negativos.

\section{DISCUSSÃ0}

A associação do CHC com as infecções pelo HBV e HCV apresenta no Brasil variações regionais. 0 HBsAg sérico varia em percentuais de $12,5 \%$ a $71,4 \%{ }^{9}$. Na amostra estudada em $88,9 \%$ encontrou-se um ou mais marcadores do $\mathrm{HBV}$ e desses, em 8,3\% em concomitância com o marcador de infecção pelo HCV. Houve predomínio da infecção pelo HBV com positividade do HBsAg de 58,3\%. Maiores percentuais têm sido encontrados em regiões da Ásia e África, onde $0 \mathrm{HBsAg}$ sérico é detectado em 45\% a 80\% dos pacientes com CHC. Em relação ao anti-HBc, apresenta-se geralmente em percentuais elevados principalmente em áreas de elevada endemicidade ${ }^{19}$. Nos pacientes ora estudados, 0 anti- $\mathrm{HBc}$ foi o marcador sorológico mais freqüente, encontrando-se positivo em $86 \%$. 0 anti-HBs e 0 antiHBc foram encontrados em $25 \%$ dos casos. 0 desaparecimento tardio do HBsAg poderia estar relacionado a sérias complicações, como $0 \mathrm{CHC}$, sendo este evento observado especialmente em pacientes masculinos e com idade acima de 45 anos ${ }^{11}$.

Encontrou-se nos casos estudados o $\mathrm{HBeAg}$ em $9,5 \%$ e 0 anti- $\mathrm{HBe}$ em 85,8\%. Nos CHC HBsAg positivos, 0 anti-HBe é mais freqüente que $0 \mathrm{HBeAg}$ que se apresenta positivo em menos de 20-35\% dos casos em conseqüência de baixos níveis de replicação viral ${ }^{21}{ }^{22}$. 0 sistema $\mathrm{HBeAg/anti-HBe}$ tem sido encontrado em percentuais de 16,6\% e 83,4\% na Espanha ${ }^{20} \mathrm{e}$ na África do Sul em 32,3 e 68,6\%22. Uma fase não replicativa da infecção pelo $\mathrm{HBV}$, antecede o CHCem pacientes $\mathrm{HBsAg}$ positivos e os marcadores séricos de replicação viral, estão presentes em percentuais inferiores a 30\% ${ }^{21}$. Na amostra estudada, 0 anti- $\mathrm{HBC}$ IgM foi encontrado em 57,1\% dos casos HBsAg positivos, semelhante ao encontrado em outros estudos ${ }^{16}$.

Os resultados dos exames biomoleculares mostraram percentuais do HBV-DNA em 37,7\% do total de casos e em $65 \%$ dos casos HBsAg positivos. Em outros relatos, o HBV-DNA foi encontrado em percentuais variáveis de $26,7 \%$ a $80 \% 1522$. Contudo, percentuais mais elevados (100\%) também têm sido encontrados ${ }^{1620}$. Não encontrou-se 0 HBV-DNA em soros de pacientes HBsAg negativos, ou com marcadores de infecção passada pelo HBV. Entretanto, outros estudos referem a presença do HBV-DNA em casos de CHCHBsAgnegativos ${ }^{1720}$. 0 anti-HCV foi positivo em 8,3\% dos pacientes e sempre associado a algum marcador do HBV. Elevada associação entre HCVe CHCtem sido encontrada em vários países, como na Itália ${ }^{5}$ Espanha ${ }^{20} \mathrm{e} \mathrm{Japão} 0^{23}$. № Brasil, observa-se uma tendência de maior participação do HCV em estados do sul e sudeste e em populações urbanas, com percentuais de anti-HCV entre 8 e $50 \%$ e freqüência média de 26,9\% ${ }^{9}$. Em 11,1\% dos pacientes, todos os marcadores foram negativos. Estes achados sugerem que outros fatores etiológicos, poderiam estar relacionados ao desenvolvimento do $\mathrm{CHC}$. Condições climáticas regionais poderiam favorecer a contaminação de alguns alimentos pelas aflatoxinas (principalmente aflatoxina B) que estariam implicadas como importantes co-fatores na gênese do $\mathrm{CHC}$. 0 percentual de etilismo observado foi semelhante a média encontrada Brasil. Encontrou-se cirrose associada em 83,3\% dos pacientes avaliados. Em um estudo multicêntrico no Brasil, ocorrência de cirrose associada ao CHCfoi encontrada em 71,2\%\%.

0 comportamento da AFP na presente casuística foi semelhante ao encontrado em regiões de alta incidência do $\mathrm{CHC}^{13}$. Encontrouse uma associação positiva entre os níveis mais elevados de AFP com o HBsAg e a presença de doença hepática crônica. Achados semelhantes foram encontrados no Zaire ${ }^{13}$ e no Japã $0^{18}$. Devido ao crescimento silencioso e reservado prognóstico do $\mathrm{CHC}$, programas com avaliações periódicas da AFP e US têm sido utilizados com conseqüente melhora na sobrevida ${ }^{12}$. Como resultados contraditórios têm sido observados em alguns locais ${ }^{5}$, questiona-se quais populações seriam beneficiadas com estes programas de investigação, qual a frequiência que estes testes devem ser realizados e se a detecção precoce realmente prolonga a sobrevida em pacientes com cirrose ${ }^{1124}$. Em algumas regiões, medidas como a vacinação de crianças contra $0 \mathrm{HBV}$ levaram a redução da incidência do $\mathrm{CHC}^{24}$. A maioria dos casos avaliados 
encontrava-se em estágio avançado de doença, sem possibilidade de terapêutica curativa. Portanto, em populações de risco, os recursos utilizados no diagnóstico precoce, ainda não são práticas de rotina, ressaltando-se a importância da implementação de medidas preventivas para as infecções virais relacionadas. A Amazônia brasileira passa por um momento de transformações eco-epidemiológicas de diversas ordens e medidas de prevenção para as hepatites B e C estão sendo aplicadas e implementadas. Por isso ressalta-se a necessidade de se monitorar prospectivamente a etioepidemiologia do CHC na região.

\section{REFERÊNCIAS BIBLIOGRÁFICAS}

1. Ayres M. BioEstat: aplicações estatísticas nas áreas das ciências biológicas e médicas. Sociedade Civil Mamirauã, Manaus, 1998.

2. Beasley RP, LIN CC, Hwang LL, Chien CS. Hepatocellular carcinoma and hepatitis B. A prospective study of 22.707 men in Taiwan. The Lancet 21:1129-1133, 1981.

3. Castells L, Vargas V, Gonzales A, Esteban R, Esteban J, Guardia J. Long interval between HCV infection and development of hepatocellular carcinoma. Liver 15:159-163, 1995.

4. Chang MH, Chen CJ, Lai MS. Universal hepatitis B vaccination in Taiwan and the incidence of hepstocelular carcinoma in children. New England Journal of Medicine 336:1855-1859,1997.

5. Colombo M, De Franchis R, Del Ninno E. Hepatocellular carcinoma in Italian pacientes with cirrhosis. The New England Journal of Medicine 325: 675-680, 1991

6. De Mitri MS, Poussin K, Baccarini P, Pontisso P, D'Errico A, Simon N, Grigioni W, Alberti A, Beaugrand M, Pisi E. HCV-associated liver cancer without cirrhosis. The Lancet 345: 413-415, 1995.

7. Fundação Nacional de Saúde. Mortalidade Brasil. 1992. Centro Nacional de Epidemiologia, Ministério da Saúde, Brasília, 1996.

8. Gonçalves CS, Pereira FEL. Tumores de fígado. In: Dani R, Castro LP (eds) Gastroenterologia Clínica. Guanabara Koogan, Rio de Janeiro, p. 14551483, 1993.

9. Gonçalves CS, Pereira FEL, Gayotto LCC. Hepatocellular carcinoma in Brazil: Report of a national survey (Florianópolis, SC, 1995). Revista do Instituto de Medicina Tropical de São Paulo 39: 165-170, 1997.
10. Hollinger FB. Hepatitis B virus. In: Knipe DM, Howley PM ( eds) Fields Virology. Lippincott-Raven Publishers, Philadelphia, p. 2739-2907, 1996.

11. Huo TI, Wu JC, Lee PC. Sero-clearance of hepatitis B surface antigen in chronic carriers does not necessarily imply a good prognosis. Hepatology 28: 231-236, 1998.

12. Ince N, Wands JR. The increasing incidence of hepatocellular carcinoma. New England Journal of Medicine 340: 798-799, 1999.

13. Kashala L0, Kalengayi MMR, Essex M. Alpha-fetoprotein human hepatocelular carcinoma: correlation with hepatitis B surface antigen expression. Cancer Investigation 10: 513-522, 1992.

14. Kew MC. Tumors of the liver. In: Zakim D, Boyer TD ( eds) Hepatology. Atextbook of Liver Desease. WB Saunders Company, Philadelphia, p.1513-1564, 1996.

15. Kim GM, Koike K, Saito I, Miyamura T, Jay G. HBx gene of hepatitis B virus induces liver cancer in trangenic mice. Nature 351:317-320, 1991.

16. Lai MC, Tong MJ, Nowicki MJ, Lee SD. Is anti-HBc IgM a useful clinical test in acients with HBsAg-positive chronic hepatitis or primary hepatocellular carcinoma? Hepatology 8: 514-517, 1988.

17. Liang TJ, Lenox JJ, Reddy KR. Viral pathogenesis of hepatocellular carcinoma in the United States. Hepatology 18: 1326-1333, 1993.

18. Nomura F, Ohnishi, K, Tanabe Y. Clinical features and prognosis of hepatocellular carcinoma with reference to serum alpha-fetoprotein levels. Analysis of 606 pacients. Cancer 64: 1700-1707, 1989.

19. Okuda K, Kojiro M, Hiroaki O. Neoplasms of de liver. In: Schift L, Schift ER (eds) Diseases of de Liver, WB, Saunders Co, Philadelphia, p. 12361396, 1993

20. Ruiz J, Sangro B, Cuende JI. Hepatitis B and C viral infeccions in pacients with hepatocelular carcinoma. Hepatology 16: 637-641, 1992.

21. Shafritz DA, Shouval D, Sherman HI, Hadziyannis SJ, Kew MC. Integration of hepatitis B virus DNA into the genome of liver cells in chronic liver disease and hepatocellular carcinoma. The New England Journal of Medicine 305: 1067-1073, 1981.

22. Sjogren MH, Dusheiko GM, Kew MC, Song E. Hepatitis B virus infection and hepatocellular carcinoma: correlation between IgM antibody to hepatitis B core antigen, hepatitis B e antigen, and hepatitis B DNA. American Journal Tropical Medicine Hygiene 39: 582-585, 1988.

23. Takano S, Yokosuka O, Imazeki F, Tagawa M, Omata, M. Incidence of hepatocellular carcinoma in chronic hepatitis B and C: A prospective study of 251 patients. Hepatology 21: 651-655, 1995.

24. Wands JR, Blum HE. Primary hepatocellular carcinoma. The New England Journal of Medicine 325: 729-731, 1991. 